\title{
A Fuzzy AHP Methodology to Analysis the Impact of Employee Motivation in Manufacturing Industry
}

\author{
Ekta Tiwari, Rajesh Singh
}

\begin{abstract}
In this competitive era where employee's performance and productivity decides his or her value, motivated employees stands on the top priority of every organization. This is because a motivated employee not only adds revenue to its organization but also helps in creating brand value as only a motivated employee can generate customer satisfaction leading to customer brand loyalty. In a developing country like ours Manufacturing sectors play a very important role in the economy of the country. Through its modern implements manufacturing sectors brought great changes in the traits of agriculture which helped the agricultural sector in modernizing itself by introducing various manufacturing tools. A motivated employee through his or her performance and productivity help the manufacturing sector lowering its cost of units produced which directly benefits the society as the product will be available to them in better quality and at cheaper rate. Thus, the performance of the employees in the manufacturing sector directly or indirectly influence the pricing policy of any product. Hence a motivated employee is way more necessary not only for the benefit of organization but for our economy and the society as whole.
\end{abstract}

Keywords: Employee motivation, productivity, manufacturing sector, customer satisfaction

\section{INTRODUCTION}

This is an International reputed journal that published research articles globally. All accepted papers should be formatted as per Journal Template. Be sure that Each author profile (min 100 word) along with photo should be included in the final paper/camera ready submission.

It is be sure that contents of the paper are fine and satisfactory. Author (s) can make rectification in the final paper but after the final submission to the journal, rectification is not possible. In the formatted paper, volume no/ issue no will be in the right top corner of the paper.

In the case of failure, the papers will be declined from the database of journal and publishing house. It is noted that: 1 . Each author profile along with photo (min 100 word) has been included in the final paper. 2. Final paper is prepared as per journal the template. 3 .

Revised Manuscript Received on December 30, 2019.

* Correspondence Author Madan Mohan Malaviya University of Technology, Gorakhpur (Uttar Pradesh) India. E-mail: Ektatiwari2774@gmail.com

Dr. Rajesh Singh*, Department of Humanities and Management Sciences, Madan Mohan Malaviya University of Technology, Gorakhpur (Uttar Pradesh) India. E-mail: rajeshsinghiitbhu@gmail.com

(c) The Authors. Published by Blue Eyes Intelligence Engineering and Sciences Publication (BEIESP). This is an open access article under the CC BY-NC-ND license (http://creativecommons.org/licenses/by-nc-nd/4.0/)
Ekta Tiwari, Department of Humanities and Management Sciences,

Contents of the paper are fine and satisfactory. Author (s) can make rectification in the final paper but after the final submission to the journal, rectification is not possible.

\section{FACTORS AFFECTING MOTIVATION OF THE EMPLOYEES}

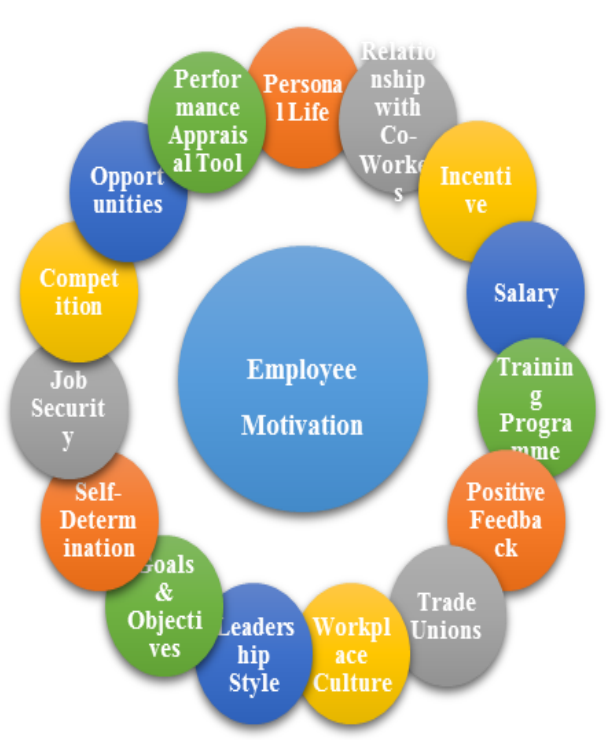

Fig 1.Factors affecting the motivation factors

\section{A. Relationship with co-workers}

Co -workers means the other employee working in the same department or organization. Co-workers plays a major role in motivating an employee because in an organization they are the only ones with whom an employee spends most of his time. ${ }^{2}$

\section{B. Incentives or rewards}

"Extra" is loved and enjoyed by everyone whether it be in monetary terms or appreciation. People love to be appreciated for their good work and same goes with the employees working in any organization. Every employee want that their efforts are being noticed and are appreciated by everyone especially where they work. ${ }^{3}$

\section{Workplace culture and working condition}

Workplace culture is the environment which is created for an employee in an organization. Workplace culture or the working condition provided for the employees plays a vital role in determining the work satisfaction which not only affects the motivation level of the employees but also influences the retention level of the employees in an organization.

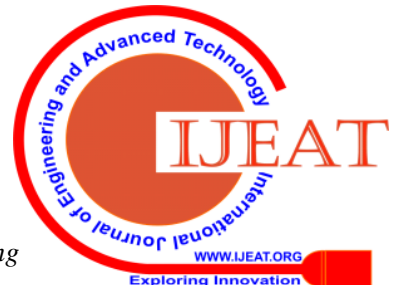




\section{Leadership style}

Leaders play a pivotal role in motivating their employees. Leaders must focus on the long term policies of the organization and should influence and persuade their employees to do their work with full enthusiasm. ${ }^{4}$

\section{E. Salary}

Salary is the powerful tool to attract and retain the best employees. The basic thing which every candidate looks before joining the organization is the salary package which he or she is going to get in return of the work performed. A good pay acts as a good motivator for the employees.

\section{F. Goals and objective}

Goals and objectives of an organization is linked to the performance of the employees. Goals and objectives give direction to the employees regarding the policies and needs of the organization. Thus a challenging goal can highly motivate the employees to perform their task in the stipulated time and with full energy.

\section{G. Competition}

Competition if taken in a positive way can motivate the employees to improve their learning and performance. Competition creates an urge among the employees perform better so that they can reduce their competition which gives them room to grow and enhance their skills and knowledge.

\section{H. Training program}

Conducting training program for the employees is becoming part and parcel of each and every organization today. Training programs are now being considered as an important function of the organization and is made sure that it is conducted and performed in a similar way as all others functions are performed.

\section{Positive feedback}

Positive and honest feedback is very essential for every employees working in the organization in order to groom themselves. Giving a positive feedback is also considered as the easiest way to motivate the employees. Feedback is not only used to give information to the employees and praise them but it also helps the employees to bring required improvement in their working pattern.

\section{J. Opportunities}

A future career growth and opportunities can highly motivate the employees to retain longer in the organization. Being stick to one position is never entertained and accepted by any employee and therefore the employees are always in a need of opportunities which may give them a new recognition and power. ${ }^{5}$

\section{K. Trade Unions}

Trade unions are the informal groups formed by the workers of the organization for the common interest of the members. Trade unions are seen to act as a powerful advocate of the employees against the organization if something wrong or injustice is done to the employees. In such situations trade unions motivates and strengthen them.

\section{Job security}

Job security is one of the most important motivational factor for the employees. Organization must make sure that the employees feel secure regarding their job in order to gain their loyalty towards the organization. Lack of job security generates a feeling of fear among the employees which directly or indirectly hampers their performance.

\section{Performance appraisal tool}

Performance appraisal tool act as a great source for employee development. Through Performance appraisal method the employees can easily recognize their strength and weakness and can work upon the factors in which they are lacking. Effective performance appraisal tool helps the employees in identifying the challenges in the job and gives them a chance to improve their performance.

\section{N. Self-determination}

Self- determination is a skill through which the person controls his life according to his own choice. Self-determination skills in an organization helps the employees to take better decisions towards the work in particular and the organization in general. Self-determination motivates the employees to perform the task within the stipulated time and with greater efficiency.

\section{O. Personal life}

Fortunately or unfortunately personal life plays a huge role in employee's motivation. It has both positive and negative impact on the motivation level of the employees. Major personal issues such as death of closed ones, end of relationship or a traumatic incident automatically drain the employee's motivation the other hand if the personal life is full of happiness it is automatically reflected in the work because the employee is both mentally and physically fit to fight the upcoming challenges in his profession.

\section{FUZZY PAIR WISE COMPARISION}

Analytical Hierarchy Process (AHP) is a multipronged decision making mechanism which is widely applied in order to evaluate and rank the complex decision problems.

The components of the paired of comparison matrix in decision making models based on the Fuzzy AHP (FAHP) are the fuzzy numbers. In fuzzy paired of comparison first the hierarchical structure is obtained proceeding to the comparison between the criteria of the same hierarchical level to the preceding one. ${ }^{6}$

Then the fuzzy linguistic terms are adopted to execute the pair wise comparison. This comparison is made on a $0-10$ scale as expressed by the triangular fuzzy number in the table given below. The conventional function of fuzzy AHP is to select the top preference from a discrete set of choices.

Triangular fuzzy numbers with bottom value, much credible value \& top most value are taken into consideration in order to reflect despondent, most acceptable and idealistic decision making environment. 
IV. FUZZY SCALE OF PRECEDENCE

\begin{tabular}{|c|c|c|c|}
\hline Semantic Variable & $\begin{array}{c}\text { Crisp } \\
\text { AHP } \\
\text { Scale }\end{array}$ & TFN & $\begin{array}{c}\text { Reciprocate of } \\
\text { TFN }\end{array}$ \\
\hline $\begin{array}{c}\text { Immensely } \\
\text { Acceptable }\end{array}$ & 9 & $(8,9,9)$ & $(1 / 9,1 / 9,1 / 8)$ \\
\hline $\begin{array}{c}\text { More Powerfully To } \\
\text { Immensely } \\
\text { Acceptable }\end{array}$ & 8 & $(7,8,9)$ & $(1 / 9,1 / 8,1 / 7)$ \\
\hline $\begin{array}{c}\text { More Powerfully } \\
\text { Acceptable }\end{array}$ & 7 & $(6,7,8)$ & $(1 / 8,1 / 7,1 / 6)$ \\
\hline $\begin{array}{c}\text { Powerfully To More } \\
\text { Powerfully } \\
\text { Acceptable }\end{array}$ & 6 & $(5,6,7)$ & $(1 / 7,1 / 6,1 / 5)$ \\
\hline $\begin{array}{c}\text { Powerfully } \\
\text { Acceptable }\end{array}$ & 5 & $(4,5,6)$ & $(1 / 6,1 / 5,1 / 4)$ \\
\hline $\begin{array}{c}\text { Moderately To } \\
\text { Powerfully } \\
\text { Acceptable }\end{array}$ & 4 & $(3,4,5)$ & $(1 / 5,1 / 4,1 / 3)$ \\
\hline $\begin{array}{c}\text { Moderately } \\
\text { Acceptable }\end{array}$ & 3 & $(2,3,4)$ & $(1 / 4,1 / 3,1 / 2)$ \\
\hline $\begin{array}{c}\text { Equally To } \\
\text { Moderately } \\
\text { Acceptable }\end{array}$ & 2 & $(1,2,3)$ & $(1 / 3,1 / 2,1)$ \\
\hline Equally Acceptable & 1 & $(1,1,1)$ & $(1,1,1)$ \\
\hline
\end{tabular}

\section{EXPERIMENTATION}

Pair wise comparison is done by each expert, once the hierarchy is developed. The main criteria weight from first expert is as shown below.

\section{A. Main Criteria Weight by First Expert}

Table 1 Main criteria weight by first expert

\begin{tabular}{|l|c|c|c|}
\hline \multicolumn{1}{|c|}{ Main criteria } & A & B & C \\
\hline Reward motivation & 0.4473 & 0.2470 & 0.2291 \\
\hline $\begin{array}{l}\text { Organizational } \\
\text { motivation }\end{array}$ & 0.5527 & 0.2808 & 0.2474 \\
\hline Attitude motivation & 0.0000 & 0.1777 & 0.1795 \\
\hline Fear motivation & 0.0000 & 0.1058 & 0.1220 \\
\hline Competence motivation & 0.0000 & 0.1132 & 0.1270 \\
\hline
\end{tabular}

After repeating the same procedure for all expert's judgment, the equation (1) for the global weights of main criteria was developed.

$$
\mathrm{W}_{\mathrm{i}}=\left(\mathrm{a}_{\mathrm{i}}\right) / \Sigma \mathrm{a}_{\mathrm{i}} \ldots \ldots
$$

during research work, corresponding weights shown in the table below are generated from the feedback established from the experts for the three motivational category with respect to each sub criteria derived by using fuzzy linguistic scale.

\section{B. Global Weights of motivational factors}

In the succeeding step, the global weights of motivational factors are computed as explained.

\begin{tabular}{|c|c|c|c|c|c|c|c|c|c|}
\hline Sub criteria & \multicolumn{3}{|c|}{ MF1 } & \multicolumn{3}{|c|}{ MF2 } & \multicolumn{3}{|c|}{ MF3 } \\
\hline & A & $\mathrm{B}$ & $\mathrm{C}$ & $\mathrm{A}$ & $\mathrm{B}$ & $\mathrm{C}$ & $\mathrm{A}$ & $\mathrm{B}$ & $\mathrm{C}$ \\
\hline Incentives & 0.051 & 0.025 & 0.024 & 0.028 & 0.017 & 0.017 & 0.028 & 0.062 & 0.024 \\
\hline Salary & 0.002 & 0.016 & 0.009 & 0.002 & 0.024 & 0.021 & 0.015 & 0.002 & 0.015 \\
\hline Training program & 0.032 & 0.027 & 0.021 & 0.019 & 0.02 & 0.019 & 0.02 & 0.028 & 0.022 \\
\hline Trade and Unions & 0.049 & 0.021 & 0.03 & 0.008 & 0.011 & 0.012 & 0.022 & 0.012 & 0.014 \\
\hline Workplace culture & 0.023 & 0.034 & 0.02 & 0.127 & 0.045 & 0.036 & 0.019 & 0.028 & 0.021 \\
\hline Leadership style & 0.031 & 0.019 & 0.018 & 0.013 & 0.019 & 0.019 & 0.011 & 0.013 & 0.019 \\
\hline Goals and objectives & 0.024 & 0.018 & 0.026 & 0.033 & 0.021 & 0.02 & 0.023 & 0 & 0.012 \\
\hline Relationship with co-workers & 0.025 & 0.03 & 0.021 & 0.009 & 0.023 & 0.023 & 0.013 & 0.009 & 0.023 \\
\hline Performance appraisal tool & 0.037 & 0.023 &.-29 & 0 & 0.01 & 0.012 & 0.014 & 0 & 0.015 \\
\hline Competition & 0.033 & 0.021 & 0.01 & 0.01 & 0.02 & 0.021 & 0.016 & 0.008 & 0.016 \\
\hline Opportunities & 0.011 & 0.026 & 0.011 & 0.006 & 0.013 & 0.014 & 0.016 & 0.012 & 0.016 \\
\hline Job security & 0.007 & 0.022 & 0.008 & 0.005 & 0.013 & 0.014 & 0.009 & 0.009 & 0.016 \\
\hline Positive feedback & 0.014 & 0.01 & 0.022 & 0.002 & 0.006 & 0.007 & 0.006 & 0.003 & 0.01 \\
\hline Self determination & 0.003 & 0.007 & 0.015 & 0.004 & 0.007 & 0.008 & 0.015 & 0.003 & 0.008 \\
\hline Personal life & 0.001 & 0.022 & 0.012 & 0.002 & 0.012 & 0.014 & 0.007 & 0.006 & 0.016 \\
\hline
\end{tabular}

Table 2 Global weights of motivational factors

\section{RESULT AND DISCUSSION}

The results are computed as reported below

\begin{tabular}{|c|c|c|c|c|c|c|c|c|c|}
\hline & \multicolumn{3}{|c|}{ MF1 } & \multicolumn{3}{|c|}{ MF2 } & \multicolumn{3}{|c|}{ MF3 } \\
\hline Sum of weights & 0.4 & 0.39 & 0.37 & 0.31 & 0.32 & 0.32 & 0.22 & 0.29 & 0.31 \\
\hline Defuzzified weight & \multicolumn{3}{|c|}{0.387} & \multicolumn{3}{|c|}{0.315} & \multicolumn{3}{|c|}{0.279} \\
\hline
\end{tabular}

Table 3 De-fuzzified weight

MF1 got the maximum score on overall criteria's. Hence

MF1 is appropriate choice 


\section{CONCLUSION}

The above multiple criterion approach has been employed to make the best decision regarding the motivational factor motivating the employees to its highest degree when considered in a manufacturing sector. The main criteria and the sub part of the main criteria displayed in the above research paper is a result of dynamic nature of environment as well as the changing perception. Experts of the respective fields have also played an important role in deciding the factors affecting motivation of the employees in the manufacturing firm. Each and every element influencing the motivation level of the employees has been examined and considered. The paradigm shift from other decision making tool to AHP has been found to be uncomplicated, less time consuming giving an advantage of less expenditure as well. AHP do not comprise of heavy and clumsy mathematical procedure making it overall an easy approach towards sophisticated decision making issues. It bears the competence to captivate the fuzziness in human belief thereby making it a viable technique.

\section{REFERENCES}

1. IBEF. Indian Manufacturing Sector: Overview and Prospects. 2013;3(6)

http://www.ibef.org/download/Indian-Manufacturing-110512.pdf.

2. Ariani DW. Relationship with Supervisor and Co-Workers, Psychological Condition and Employee Engagement in the Workplace. J Bus Manag. 2015;4(3):34-47. doi:10.12735/jbm.v4i3p34

3. Abdullah N, A. Shonubi O, Hashim R, Hamid N. Recognition and Appreciation and its Psychological Effect on Job Satisfaction and Performance in a Malaysia IT Company: Systematic Review. IOSR J Humanit Soc Sci. 2016;21(09):47-55. doi:10.9790/0837-2109064755

4. Gabriela HM. The Leadership's Role in Motivating Employees. Ovidius Univ Ann Econ Sci Ser. 2017;XVII(1):296-301.

5. Parvaiz T, Ahmed O. Suistaining the Growth of Employee: Motivation and Career Development in Organization. Munich Pers RePEc Arch Arch. 2016;(69728):1-12.

6. Wang YM, Chin KS. Fuzzy analytic hierarchy process: A logarithmic fuzzy preference programming methodology. Int J Approx Reason. 2011;52(4):541-553. doi:10.1016/j.ijar.2010.12.004

\section{AUTHORS PROFILE}

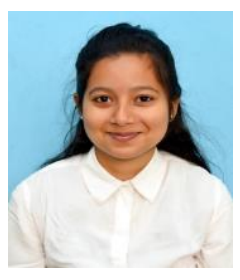

Name-Ekta Tiwari

Date Of Birth- 07/01/1997

Place Of Birth- Patna

Address- House No: 285, Gaytri Nagar, Post -

Kunraghat, Gorakhpur, Uttar Pradesh

Nationality- Indian Pin: 273008

Educational Qualification:

Currently Persuing Mba Year- 2018-2020

Institute- Madan Mohan Malaviya University Of Technology (Gorakhpur, Up)

Humanities And Management Sciences Department

Graduation In Bachelor Of Science (Physics)

Year- 2015-2018

Institute-Vinobha Bhave University (Hazaribhag, Jharkhand) High

School

Year- 2015

Institute- De-Nobili School Sindri (Icse)

(Dhanbad, Jharkhand)

Intermediate Year-2013

Institute- De-Nobili School Sindri (Icse)

(Dhanbad, Jharkhand)

Experience: 2 Months

Programme- Summer Internship Programme Institution- The Gate Academy (Bangalore) Area Of Training - Recruitment And Selection

Name-Dr. Rajesh Singh

\section{Nationality- Indian}

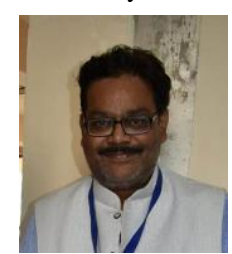

Educational Qualification:

Currently Working As Associate

Professor (Contract) Joined-2018

Institute- Madan Mohan Malaviya University Of

Technology (Gorakhpur, Up)

Humanities And Management Sciences Department

Phd In The Field Of Industrial Management Area

Institution- Iit Bhu, Varanasi, Uttar Pradesh

Post Graduation In Management Of Business Administration

Institute- Ims Davv, Indore, Madhya Pradesh

Graduation In Bachelor Of Technology

Year- 1991-1995

Institute- Knit Sultanpur

Experience: Worked As Human Resource Professional 